(c) American Dairy Science Association, 2005.

\title{
Impact of Maturity Rate of Daughters on Genetic Ranking of Holstein Bulls
}

\author{
H. D. Norman, J. R. Wright, R. L. Powell, and P. M. VanRaden \\ Animal Improvement Programs Laboratory, Agricultural Research Service, \\ USDA, Beltsville, MD 20705-2350
}

\begin{abstract}
If genetic evaluations are calculated with a singletrait repeatability model, evaluation changes may be attributed in part to bulls that have daughters that deviate considerably from the typical response to aging. Differences in maturity rate of bull daughters were examined to determine whether they influence change in bull evaluations. Standardized milk records for Holsteins that first calved between 1960 and 1998 were used to calculate 12 tailored predicted transmitting abilities (PTA) for each bull. Predicted transmitting abilities were tailored from combinations of 4 annual cut-off dates and 3 parities. Date screening selected cows first calving before January of 1996, 1997, 1998, or 1999. Parity screening selected milk records from the first 1, 2, or 3 parities. Therefore, 4 evaluations $\left(\mathrm{PTA}_{1}\right)$ included only first-parity records available for daughters and contemporaries prior to the respective years designated. Four more evaluations $\left(\mathrm{PTA}_{1,2}\right)$ included the records from the first 2 parities for cows first calving prior to those same year cutoffs; likewise, the last 4 evaluations $\left(\mathrm{PTA}_{1,2,3}\right)$ included records from the first 3 parities. Stability of bull evaluations (standard deviations of differences as well as correlations between bull evaluations) across time was compared. Bulls born after 1984 with $\geq 500$ daughters were of interest because of the high precision of evaluations and recent activity. Tailored PTA of those bulls had more uniformity across years in mean records per daughter than did official USDA PTA. Standard deviation of differences in $\mathrm{PTA}_{1}$, $\mathrm{PTA}_{1,2}$, and $\mathrm{PTA}_{1,2,3}$ for milk between evaluation years 1996 and 1997 were 28, 28, and $27 \mathrm{~kg}$ compared with $63 \mathrm{~kg}$ for official evaluations; similarly, between 1996 and 1999, SD were 36,32 , and $32 \mathrm{~kg}$ compared with 80 kg. Results suggested that a modification to the current evaluation model to account for maturity rate should reduce fluctuations in individual bull PTA across time and may improve accuracy of evaluations.
\end{abstract}

Received December 30, 2004.

Accepted May 31, 2005.

Corresponding author: H. D. Norman; e-mail: dnorman@aipl. arsusda.gov.
(Key words: genetic evaluation, maturity rate, milk yield, parity)

Abbreviation key: PTA 1 = PTA based on first-parity records, PTA $_{1,2}=$ PTA based on first- and second-parity records, PTA $\mathbf{A}_{1,2,3}=$ PTA based on first-, second-, and third-parity records, $\mathbf{P T A _ { 2 }}=$ PTA for second-parity lactation, $\mathbf{P T A} \mathbf{A}_{3}=$ PTA for third-parity lactation.

\section{INTRODUCTION}

In the 1970 s, most countries used only first-parity lactation records for ranking bulls for milk and fat even though cows were usually evaluated using multiple records. Bull evaluations from USDA were one exception as they included later-parity records of daughters as early as 1935 (Division of DHI Investigations, 1937). Two arguments against the use of later-parity records were that 1) such records could cause bias if not modeled properly and 2) waiting for later-parity information increased generation interval. The first argument is not valid if all cows included in the genetic evaluation have first-parity records present and appropriate age adjustment and repeatability parameters for lactation yields are used in deriving the evaluations (Henderson et al., 1959). The second argument is also weak if selection decisions are based on information from first and later parities as soon as available.

Including information from multiple parities (often the first 3 or 5) in genetic evaluations has increased over the last 2 decades and is now standard practice for most countries that provide national evaluations to the International Bull Evaluation Service (2005). Pressure from producers provided some impetus to include more than single-parity yield, along with a desire by evaluation centers to use animal models to evaluate males and females together.

Cassell and McDaniel (1983) reviewed the literature on the value of later records in bull evaluations. Cassell et al. (1983) found that the standard deviation (SD) of the differences between first and later genetic evaluations of bulls was 58\% as large as the SD of genetic differences among bulls. Later, Cassell et al. (1985) illustrated the probable influence of culling by simulat- 
Table 1. Estimated genetic correlations among parities for milk yield by country.

\begin{tabular}{|c|c|c|c|c|c|}
\hline \multirow[b]{2}{*}{ Country } & \multirow[b]{2}{*}{ Breed } & \multicolumn{3}{|c|}{ Correlations between parities } & \multirow{2}{*}{$\begin{array}{l}\text { Reference for methodology used } \\
\text { to calculate genetic correlations }\end{array}$} \\
\hline & & 1,2 & 1,3 & 2,3 & \\
\hline Canada $^{1}$ & Holstein & 0.77 & 0.68 & 0.83 & Jamrozik et al., 1998 \\
\hline Belgium $^{1,2}$ & Holstein & 0.87 & 0.85 & 0.90 & Auvray and Gengler, 2002 \\
\hline Denmark & Jersey & 0.98 & 0.94 & 0.99 & Guo et al., 2002 \\
\hline France & Holstein & 0.91 & 0.91 & 0.99 & Druet et al., 2005 \\
\hline Germany $^{1}$ & Holstein & 0.84 & 0.84 & 0.97 & Liu et al., 2000 \\
\hline Israel & Holstein & 0.89 & 0.88 & 0.98 & Weller and Ezra, 2004 \\
\hline Poland $^{1}$ & Holstein & 0.92 & 0.82 & 0.93 & Strabel et al., 2004 \\
\hline Sweden & Holstein & 0.90 & 0.90 & 0.99 & Carlen et al., 2004 \\
\hline The Netherlands ${ }^{1,2}$ & All breeds & 0.85 & 0.80 & 0.87 & de Roos et al., 2001 \\
\hline United States & Holstein & 0.93 & 0.90 & 0.99 & Wiggans and VanRaden, 2004a \\
\hline
\end{tabular}

\footnotetext{
${ }^{1}$ Correlations are those reported to the International Bull Evaluation Service (2005) as of February 2005.

${ }^{2}$ Correlations for Belgium are for the Walloon area; the Flemish area of Belgium is included with The Netherlands.
}

ing lactation records, imposing culling, and calculating evaluations based on various alternatives. Abdallah and McDaniel (2002) examined the changes in PTA from first to later lactation using USDA evaluations at different dates. Because of ongoing changes in evaluation methods across time and the challenge to match field evaluations with the desired daughters and records for the comparison of interest, conclusions using this approach were limited and somewhat difficult to interpret. Abdallah and $\mathrm{McDaniel}$ reported that correlated genetic effects are probably needed for first and later parities in the genetic evaluation model to remove the instability across time.

When later-parity yields are included in genetic evaluations, one of two assumptions is made: 1) yields from different parities are measures of the same trait; i.e., repeated measures in a single-trait evaluation, or 2) yields from different parities represent correlated traits in a multiple-trait evaluation. Genetic correlations less than unity indicate that genetic control for later parities is partially independent of that for first parity. Because the repeatability model assumes genetic correlations of 1.0 between all parities, it may produce results that are less desirable than alternative choices if those correlations are $<1.0$.

Modeling separate predictions for individual parities or simply for first and later parities is becoming more frequent and is done in several countries (International Bull Evaluation Service, 2005). The advantage of doing so depends on how distant the genetic correlations among parities are from 1.0. Table 1 shows recent estimates of genetic correlations for milk yield among the first 3 parities in 10 countries. Results ranged from 0.68 to 0.83 for Canadian Holsteins to 0.94 to 0.99 for Danish Jerseys. The differences among estimates most likely result from differences in estimation methods rather than from large differences in population param- eters as evidenced by more similar estimates during the 1960s and 1970s than in recent years and lower estimates from random regression methods. Strandberg (1991) summarized earlier literature estimates of genetic correlations between parities for milk yield and found they averaged 0.81 between first and second parity, 0.77 between first and third, and 0.89 between second and third.

Predictions for separate parities could be released for each bull (Jamrozik et al., 1998; F. Miglior and F. Canavesi, personal communication, 2004), but this approach would expand considerably the number of traits for which to select. Deriving predictions for individual parities could improve accuracy of estimated genetic merit; however, the utility of separate parity estimates is less clear, especially if several parities are estimated. Justification for herd-specific economic weights on individual parities based on different management styles among dairy enterprises has never been presented. If modeling separate parity effects was determined to be necessary, combining those effects into a single index for producers might be preferable to providing results for separate parities.

Each set of bull daughters provides a sample of the genes of their sire, and the daughters added in each subsequent evaluation received either a superior or an inferior Mendelian sample compared with expectation. Changes in bull evaluations across time occur when 1) additional daughters calve and are included, 2) lactations are added from later parities on the same daughters, and 3) in-progress records obtain more DIM. All 3 occurrences also increase PTA reliability. A bull PTA also can change if information from a bull's daughter is deleted because of the discovery of a pedigree error; however, such changes lower computed PTA reliability. Despite the lower computed reliability, the evaluations generally should be more accurate if erroneous data are 
removed. A pedigree correction influences more than a single sire's evaluation. Although the frequency of pedigree change is low, the impact of such changes sometimes is evident when little new daughter information is added for a sire.

The preponderance of daughter information in evaluations for bulls that start to add second-crop daughters shifts from later- to first-parity records. Subsequently, the percentage of daughters with later-parity records increases. The impact on bull PTA of such shifts when using a single-trait evaluation model has seldom, if ever, been examined. If the model fits the data well, changes in subsequent evaluations are a function of the increase in reliability; therefore, bull evaluations with high reliabilities should be more stable than those with lower reliabilities. However, several studies (Cassell et al., 1985; Powell and Norman, 2001; Powell et al., 2004) revealed that observed changes exceeded those expected. Changes in evaluations that were larger than expected could be attributed to a few bulls with daughters that deviate considerably from a typical response to aging (maturity rate) and that had shifts in the percentage of daughters with later-parity records. The change could be substantial in conjunction with a minimal increase in reliability. Changes across time due to lack of fit of the evaluation model would be most apparent for high-reliability evaluations because of smaller changes from Mendelian sampling.

The PTA of a bull that is genetically average for maturity rate is not expected to change greatly when additional information becomes available for lactations for later parities of daughters. However, bulls that are genetically extreme for maturity rate are expected to have the largest PTA changes when their evaluations include later-parity information.

If genetic differences in maturity rate of daughters have a large impact on ranking of bulls, a modification of the evaluation model may be needed to treat yield from different parities as different traits. Such a modification could reduce variation in evaluations across time, thereby raising breeder confidence that released evaluations were reliable estimates of the true genetic merit of bulls.

The primary objective of this study was to determine if bulls differ in maturity rate of daughters. A secondary purpose was to determine whether differences in maturity rate affected bull rankings by the USDA-DHIA animal model over time.

\section{MATERIALS AND METHODS}

\section{Data}

Records of Holstein cows in the USDA Animal Improvement Programs Laboratory (Beltsville, MD) na- tional database with a first-parity calving date between January 1960 and December 1998 were used to calculate genetic evaluations for their sires. All DHI records had been standardized for age-parity, calving month, previous days open, and daily milking frequency (Animal Improvement Programs Laboratory, 2005); records in progress and completed records had been projected to $305 \mathrm{~d}$ through best prediction (VanRaden, 1997). Only first-, second-, and third-parity milk records from a cow's first herd were included; any later-parity record for which a record for the previous parity was missing was excluded. Records through October 8, 2003, were used as needed to meet designated parity requirements.

Genetic evaluations were examined for bulls that had $\geq 10, \geq 20, \geq 50, \geq 100, \geq 200$, or $\geq 500$ daughters with milk records for all 3 parities. To focus on bulls with considerable daughter activity, i.e., adding progeny information between 1996 and 1999, separate examinations were completed for those bulls born after 1984 .

\section{Calculation of Bull PTA for Milk Yield by Parity}

Three types of PTA for milk yield were calculated for each bull using the current USDA-DHIA animal model evaluation system (Wiggans and VanRaden, 1989) and records of the bull's daughters: 1) PTA based on firstparity records (PTA $)$; 2) PTA based on first- and second-parity records (PTA 1,2$)$; and 3) PTA based on first-, second-, and third-parity records $\left(\mathbf{P T A}_{\mathbf{1 , 2 , 3}}\right)$. Those 3 types of PTA are referred to as tailored because the evaluations were customized to reveal the impact of maturity rate. If PTA had been calculated with records only from individual parities (e.g., second without first and third), PTA based on second-parity (PTA 2 ) or thirdparity $\left(\mathbf{P T A}_{\mathbf{3}}\right)$ records would have been biased because cows with high milk yield during early parities are less likely to be culled (Keown et al., 1976). Including all records on which female culling was based protects the evaluations from such bias if appropriate methods have been applied to account for repeatability and age adjustment (Henderson et al., 1959).

Because $\mathrm{PTA}_{1,2}$ and $\mathrm{PTA}_{1,2,3}$ were based on cumulative records from 2 and 3 parities, respectively, they, along with $\mathrm{PTA}_{1}$, were used to predict the individual parity contributions of daughters; i.e., $\mathrm{PTA}_{2}$ and $\mathrm{PTA}_{3}$. The following relationships were assumed:

$$
\mathrm{PTA}_{1,2}=\left(\mathrm{n}_{1} \mathrm{PTA}_{1}+\mathrm{n}_{2} \mathrm{PTA}_{2}\right) /\left(\mathrm{n}_{1}+\mathrm{n}_{2}\right)
$$

and

$\mathrm{PTA}_{1,2,3}=\left(\mathrm{n}_{1} \mathrm{PTA}_{1}+\mathrm{n}_{2} \mathrm{PTA}_{2}+\mathrm{n}_{3} \mathrm{PTA}_{3}\right) /\left(\mathrm{n}_{1}+\mathrm{n}_{2}+\mathrm{n}_{3}\right)$ 
where $\mathrm{n}_{1}, \mathrm{n}_{2}$, and $\mathrm{n}_{3}=$ number of bull daughters with first-, second-, and third-parity records, respectively. Thus,

$$
\mathrm{PTA}_{2}=\left[\left(\mathrm{n}_{1}+\mathrm{n}_{2}\right) \mathrm{PTA}_{1,2}-\mathrm{n}_{1} \mathrm{PTA}_{1}\right] / \mathrm{n}_{2},
$$

and

$\mathrm{PTA}_{3}=\left[\left(\mathrm{n}_{1}+\mathrm{n}_{2}+\mathrm{n}_{3}\right) \mathrm{PTA}_{1,2,3}-\mathrm{n}_{1} \mathrm{PTA}_{1}-\mathrm{n}_{2} \mathrm{PTA}_{2}\right] / \mathrm{n}_{3}$.

For example, if all daughters had second lactations, then $\mathrm{PTA}_{2}$ would have been $2 \mathrm{PTA}_{1,2}-\mathrm{PTA}_{1}$. In such a case, parity contributions from $\mathrm{PTA}_{1}$ and $\mathrm{PTA}_{2}$ would have had equal influence on $\mathrm{PTA}_{1,2}$.

\section{Relationships Among Bull PTA Across Parities}

Correlations between the various tailored and official USDA-DHIA PTA for January 1999 were derived with a fixed effect for birth year of bull in the model. The SD of bull differences for milk yield between parities was compared with the SD of difference among bulls within parity to provide an indication of the importance of differences in maturity rate relative to the genetic opportunity when maturity differences were ignored.

The tailored bull PTA were examined to determine if bulls with daughter yields that either increased or decreased from first to second parity continued to show the same trend from second to third; i.e., was $\mathrm{PTA}_{1,2}$ generally intermediate to $\mathrm{PTA}_{1}$ and $\mathrm{PTA}_{1,2,3}$ if $\mathrm{PTA}_{1}$ and $\mathrm{PTA}_{1,2,3}$ indicated that daughters appeared to mature at a rate considerably different from normal. Regression of $\mathrm{PTA}_{1,2}-\mathrm{PTA}_{1}$ on $\mathrm{PTA}_{1,2,3}-\mathrm{PTA}_{1}$ should indicate how closely yield from second parity resembled yields from first vs. third parity. Likewise, regression of $\mathrm{PTA}_{2}-\mathrm{PTA}_{1}$ on $\mathrm{PTA}_{3}-\mathrm{PTA}_{1}$ should provide another indication of the relationship among parities. This examination should reveal whether adding a single effect for trend in maturity rate to the evaluation model could account for trends in yield from first to later parities (Guo et al., 2002) or whether separate model effects would be needed for each parity (Schaeffer et al., 2000) because bulls deviated substantially from a biological progression with age. A multitrait model was not investigated, and concurrent research by Wiggans and VanRaden $(2004 a, b)$ on a random regression approach indicated no improvement in predictability of genetic merit compared with current evaluation methods for US dairy cattle.

Bulls with $\geq 500$ daughters were of particular interest in reviewing this maturity progression because their true transmitting abilities for individual-parity yields should be predicted with high precision. If bulls with highly accurate evaluations do not appear to deviate
Table 2. Standard deviations (kg) of tailored and official PTA milk for bulls born after 1984 with $\geq 10$ or $\geq 500$ daughters that first calved before $1999 .^{1}$

\begin{tabular}{lll}
\hline & $\begin{array}{l}\text { Bulls with } \geq 10 \\
\text { daughters } \\
(\mathrm{n}=26,296)\end{array}$ & $\begin{array}{l}\text { Bulls with } \geq 500 \\
\text { daughters } \\
(\mathrm{n}=2796)\end{array}$ \\
\hline PTA & 463 & 539 \\
$\mathrm{PTA}_{1}$ & 456 & 529 \\
$\mathrm{PTA}_{1,2}$ & 459 & 531 \\
$\mathrm{PTA}_{1,2,3}$ & 469 & 526 \\
$\mathrm{PTA}_{2}$ & 510 & 552 \\
$\mathrm{PTA}_{3}$ & 501 & 574 \\
$\mathrm{PTA}_{\text {official }}$ & & \\
\hline
\end{tabular}

${ }^{1} \mathrm{PTA}_{1}=\mathrm{PTA}$ based on first-parity records, $\mathrm{PTA}_{1,2}=\mathrm{PTA}$ based on first- and second-parity records, PTA $_{1,2,3}=$ PTA based on first-, second-, and third-parity records, $\mathrm{PTA}_{2}=\mathrm{PTA}$ for second-parity lactation, $\mathrm{PTA}_{3}=\mathrm{PTA}$ for third-parity lactation, and $\mathrm{PTA}_{\text {official }}=$ official USDA-DHIA PTA.

from a biological progression for maturity, any differences apparent among bull evaluations with lower accuracy also are not likely to result from real biological deviations.

\section{Parity Effect on Stability of Sire Evaluations}

Tailored milk evaluations were calculated for January 1996, 1997, and 1998 in addition to January 1999, so that stability of tailored and official USDA-DHIA evaluations could be compared across time. Annual evaluations included accumulated milk records of cows with a first calving date through December prior to the designated evaluation year. More uniformity within bulls in the mean number of lactations per daughter across time in the tailored genetic evaluations than in the official evaluations should produce more uniformity in the contribution of information coming from individual parities.

Correlations were calculated across years to determine how information from individual parities contributed to variation in bull evaluations. A birth date restriction was imposed (bulls born after 1984) to focus on bulls with considerable new information added between 1996 and 1999.

Indicators of evaluation stability across time were the SD of differences between the various milk evaluations as well as the correlations between them. The $\mathrm{SD}$ of difference of $\mathrm{PTA}_{1}, \mathrm{PTA}_{1,2}$, and $\mathrm{PTA}_{1,2,3}$ between years were compared with those of the official USDADHIA milk evaluations released in January or February of corresponding years. The official evaluations included information from available milk records through fifth parity.

\section{RESULTS AND DISCUSSION}

The SD for tailored and official PTA are shown in Table 2 for the 26,296 bulls with $\geq 10$ daughters and 
Table 3. Correlations within bull birth year between PTA milk for tailored evaluations from different parities and official evaluations for bulls with $\geq 10$ (above diagonal) or $\geq 500$ daughters (below diagonal) that first calved before $1999 .^{1}$

\begin{tabular}{lllllll}
\hline & $\mathrm{PTA}_{1}$ & $\mathrm{PTA}_{1,2}$ & $\mathrm{PTA}_{1,2,3}$ & $\mathrm{PTA}_{2}$ & $\mathrm{PTA}_{3}$ & PTA $_{\text {official }}$ \\
\hline PTA $_{1}$ & 1.000 & 0.961 & 0.937 & 0.785 & 0.681 & 0.915 \\
PTA $_{1,2}$ & 0.979 & 1.000 & 0.986 & 0.926 & 0.749 & 0.958 \\
PTA $_{1,2,3}$ & 0.962 & 0.996 & 1.000 & 0.926 & 0.848 & 0.970 \\
PTA $_{2}$ & 0.875 & 0.955 & 0.970 & 1.000 & 0.744 & 0.891 \\
PTA $_{3}$ & 0.832 & 0.910 & 0.944 & 0.955 & 1.000 & 0.817 \\
PTA $_{\text {official }}$ & 0.949 & 0.986 & 0.993 & 0.966 & 0.948 & 1.000 \\
\hline
\end{tabular}

${ }^{1} \mathrm{PTA}_{1}=$ PTA based on first-parity records, $\mathrm{PTA}_{1,2}=$ PTA based on first- and second-parity records, PTA $_{1,2,3}=$ PTA based on first-, second-, and third-parity records, PTA 2 = PTA for second-parity lactation, $\mathrm{PTA}_{3}=$ PTA for third-parity lactation, and PTA official = official USDA-DHIA PTA.

2796 bulls with $\geq 500$ daughters that had evaluations for all 3 parities. The SD of the various PTA milk for bulls with $\geq 10$ daughters were similar ( 456 to $469 \mathrm{~kg}$ ) except that SD for $\mathrm{PTA}_{3}$ and $\mathrm{PTA}_{\text {official }}$ were somewhat higher $(510$ and $501 \mathrm{~kg}$ ). The SD for bulls with $\geq 500$ daughters had a similar pattern but were 8 to $16 \%$ greater than for bulls with $\geq 10$ daughters.

\section{Relationships Among Bull PTA Across Parities}

Correlations calculated within birth year of bull between all tailored and official bull PTA from daughters that first calved from January 1960 through December 1998 are in Table 3 for bulls with $\geq 10$ or $\geq 500$ daughters. The correlations were higher between $\mathrm{PTA}_{1}$ and $\mathrm{PTA}_{1,2}$ ( 0.961 for bulls with $\geq 10$ daughters and 0.979 for bulls with $\geq 500$ daughters) than between $\mathrm{PTA}_{1}$ and $\mathrm{PTA}_{1,2,3}$ (0.937 and 0.962) as expected, because the greater the separation between parities, the more the genetic correlation is expected to deviate from 1.0 (Strandberg, 1991). Those correlations were higher than between $\mathrm{PTA}_{1}$ and the individual-parity contributions of $\mathrm{PTA}_{2}$ or $\mathrm{PTA}_{3}$ (0.681 to 0.875 ), which was also expected because the first-parity records were not included as in $\mathrm{PTA}_{1,2}$ and $\mathrm{PTA}_{1,2,3}$. The $\mathrm{PTA}_{\text {official }}$ had the highest correlations with $\mathrm{PTA}_{1,2,3}$ both for bulls with $\geq 10$ daughters
(0.970) and those with $\geq 500$ daughters (0.993); both PTA included information from a high percentage of the same records.

The SD of differences in PTA based on different parities and calculated within birth year of bull (Table 4) are an alternate representation of the relationships shown in Table 3. Consistently, if the correlation between PTA was high, the SD of differences in PTA was low.

The SD of differences between parities $\left(\mathrm{PTA}_{3}-\mathrm{PTA}_{1}\right)$ was compared with the SD of differences among bulls within parity $\left(\mathrm{PTA}_{1,2,3}\right)$ to show the importance of differences in maturity rate relative to overall genetic opportunity. Although several representations were possible, comparison of SD of $\left(\mathrm{PTA}_{3}-\mathrm{PTA}_{1}\right)$ with $\mathrm{SD}$ of $\mathrm{PTA}_{1,2,3}$ was chosen. The ratio was 0.55 (253/459), which agrees well with Cassell et al. (1983), who found that the SD of the differences between first and later genetic evaluations of bulls was 58\% as large as the SD of genetic differences among bulls. The manner of deriving differences in maturity rates in this study differed from that used in all previous studies (e.g., those in Table 1); therefore, comparison of the magnitude of differences is difficult.

The coefficient for regression of the difference between $\mathrm{PTA}_{1,2}$ and $\mathrm{PTA}_{1}$ on the difference between

Table 4. Standard deviations of differences $(\mathrm{kg})$ between PTA milk for tailored evaluations from different parities and official evaluations for bulls with $\geq 10$ (above diagonal) or $\geq 500$ daughters (below diagonal) that first calved before $1999 .^{1}$

\begin{tabular}{lcccccc}
\hline & $\mathrm{PTA}_{1}$ & $\mathrm{PTA}_{1,2}$ & $\mathrm{PTA}_{1,2,3}$ & $\mathrm{PTA}_{2}$ & $\mathrm{PTA}_{3}$ & PTA $_{\text {official }}$ \\
\hline PTA $_{1}$ & - & 79 & 100 & 193 & 253 & 127 \\
$\mathrm{PTA}_{1,2}$ & 64 & - & 46 & 114 & 225 & 97 \\
$\mathrm{PTA}_{1,2,3}$ & 85 & 28 & - & 114 & 179 & 84 \\
$\mathrm{PTA}_{2}$ & 153 & 89 & 73 & - & 231 & 147 \\
$\mathrm{PTA}_{3}$ & 179 & 129 & 102 & 93 & - & 196 \\
PTA $_{\text {official }}$ & 111 & 73 & 59 & 96 & 102 & - \\
\hline
\end{tabular}

${ }^{1} \mathrm{PTA}_{1}=$ PTA based on first-parity records, $\mathrm{PTA}_{1,2}=$ PTA based on first- and second-parity records, $\mathrm{PTA}_{1,2,3}=$ PTA based on first-, second-, and third-parity records, $\mathrm{PTA}_{2}=$ PTA for second-parity lactation, $\mathrm{PTA}_{3}=$ PTA for third-parity lactation, and PTA official = official USDA-DHIA PTA. 
Table 5. Regression coefficients (b) and SE for difference between second- and first-parity PTA on difference between third- and first-parity PTA by cumulative- or individual-parity PTA. ${ }^{1}$

\begin{tabular}{|c|c|c|c|c|c|}
\hline \multirow[b]{2}{*}{ Daughters } & \multirow[b]{2}{*}{ Bulls } & \multicolumn{2}{|c|}{$\begin{array}{c}\mathrm{PTA}_{1,2}-\mathrm{PTA}_{1} \text { on } \\
\mathrm{PTA}_{1,2,3}-\mathrm{PTA}_{1}\end{array}$} & \multicolumn{2}{|c|}{$\begin{array}{c}\mathrm{PTA}_{2}-\mathrm{PTA}_{1} \text { on } \\
\mathrm{PTA}_{3}-\mathrm{PTA}_{1}\end{array}$} \\
\hline & & $\mathrm{b}$ & $\mathrm{SE}$ & $\mathrm{b}$ & $\mathrm{SE}$ \\
\hline$\geq 10$ & 26,296 & 0.71 & 0.002 & 0.37 & 0.004 \\
\hline$\geq 20$ & 25,178 & 0.71 & 0.002 & 0.38 & 0.004 \\
\hline$\geq 50$ & 15,963 & 0.71 & 0.003 & 0.43 & 0.005 \\
\hline$\geq 100$ & 6173 & 0.72 & 0.003 & 0.58 & 0.007 \\
\hline$\geq 200$ & 4214 & 0.73 & 0.003 & 0.68 & 0.008 \\
\hline$\geq 500$ & 2796 & 0.72 & 0.003 & 0.73 & 0.008 \\
\hline
\end{tabular}

${ }^{1} \mathrm{PTA}_{1}=$ PTA based on first-parity records, $\mathrm{PTA}_{1,2}=$ PTA based on first- and second-parity records, $\mathrm{PTA}_{1,2,3}=$ PTA based on first-, second-, and third-parity records, $\mathrm{PTA}_{2}=$ PTA for second-parity lactation, and $\mathrm{PTA}_{3}=$ PTA for third-parity lactation.

$\mathrm{PTA}_{1,2,3}$ and $\mathrm{PTA}_{1}$ for bulls with $\geq 10$ daughters was 0.71 with a standard error of 0.002 (Table 5 ). The same regression coefficient for those bulls that had true transmitting ability predicted with higher precision (bulls with $\geq 500$ daughters) was $0.72 \pm 0.003$. Those regression coefficients confirm that milk yield from second parity resembles yield from third parity more closely than yield from first parity; i.e., milk yield from second and third parities is influenced by more of the same genes than is yield from first and second parities. Most studies reviewed by Strandberg (1991) also reported higher genetic correlations between yields from second and third parities than between those from first and second parities. Regression coefficients based on individual-parity ( $\mathrm{PTA}_{2}$ and $\left.\mathrm{PTA}_{3}\right)$ instead of cumulativeparity $\left(\mathrm{PTA}_{1,2}\right.$ and $\left.\mathrm{PTA}_{1,2,3}\right)$ contributions increased from $0.37 \pm 0.004$ to $0.73 \pm 0.008$ for bulls with $\geq 10$ to $\geq 500$ daughters, respectively. This result was not expected. Differences observed for individual-parity contributions provided highly useful information for bulls with high reliabilities but may not do the same for bulls with few daughters.
Table 6 provides insight into consistency of differences in maturity rate; i.e., where second-parity estimates were positioned in relation to first and third. The $\mathrm{PTA}_{1,2}$ were nearly always intermediate to $\mathrm{PTA}_{1}$ and $\mathrm{PTA}_{1,2,3}$ for bulls with $\geq 500$ daughters and with large differences between $\mathrm{PTA}_{1}$ and $\mathrm{PTA}_{1,2,3}$. In contrast, when little difference existed between $\mathrm{PTA}_{1}$ and $\mathrm{PTA}_{1,2,3}, \mathrm{PTA}_{1,2}$ was usually outside the range of the other 2 but more frequently closer to $\mathrm{PTA}_{1,2,3}$ than to $\mathrm{PTA}_{1}$.

\section{Parity Effect on Stability of Bull Evaluations}

For bulls born after 1984, correlations between years from 1996 through 1999 (Table 7) were examined for each of the tailored-parity and official PTA for the 8072 bulls with $\geq 10$ daughters and the 211 bulls with $\geq 500$ daughters that calved before each of those years. The longer the time between evaluation years, the lower the correlations. That relationship was expected because change in evaluations is a function of the increase in reliability; i.e., the amount of information added. Be-

Table 6. Numbers of bulls with $\geq 500$ daughters and with second-parity PTA milk (kg) intermediate to firstand third-parity PTA milk by maturity rate of daughters. ${ }^{1}$

\begin{tabular}{|c|c|c|c|}
\hline \multirow[b]{2}{*}{$\mathrm{PTA}_{1,2,3}-\mathrm{PTA}_{1}$} & \multicolumn{3}{|c|}{ Number of bulls } \\
\hline & $\begin{array}{l}\mathrm{PTA}_{1,2}<\mathrm{PTA}_{1} \\
\text { and PTA } \\
1,2,3\end{array}$ & $\begin{array}{l}\mathrm{PTA}_{1,2} \\
\text { intermediate to } \\
\mathrm{PTA}_{1} \text { and } \mathrm{PTA}_{1,2,3}\end{array}$ & $\begin{array}{l}\mathrm{PTA}_{1,2}>\mathrm{PTA}_{1} \\
\text { and PTA } \\
1,2,3\end{array}$ \\
\hline 110 to 295 & 0 & 227 & 4 \\
\hline 60 to 109 & 0 & 314 & 35 \\
\hline 20 to 59 & 11 & 274 & 112 \\
\hline-10 to 19 & 106 & 82 & 209 \\
\hline-40 to -11 & 122 & 238 & 69 \\
\hline-80 to -41 & 47 & 402 & 5 \\
\hline-130 to -81 & 12 & 369 & 1 \\
\hline-295 to -131 & 1 & 224 & 0 \\
\hline
\end{tabular}

${ }^{1} \mathrm{PTA}_{1}=$ PTA based on first-parity records, $\mathrm{PTA}_{1,2}=$ PTA based on first- and second-parity records, and $\mathrm{PTA}_{1,2,3}=$ PTA based on first-, second-, and third-parity records. 
Table 7. Correlations between PTA milk for evaluations tailored to different parities and official evaluations for bulls born after 1984 with $\geq 10$ (above diagonal; $\mathrm{n}=8072$ ) or $\geq 500$ daughters (below diagonal; $\mathrm{n}=211$ ) that first calved before 1996, 1997, 1998, or $1999 .^{1}$

\begin{tabular}{|c|c|c|c|c|c|}
\hline & \multirow[b]{2}{*}{ Year } & \multicolumn{4}{|c|}{ Year } \\
\hline & & 1996 & 1997 & 1998 & 1999 \\
\hline \multirow[t]{4}{*}{$\mathrm{PTA}_{1}$} & 1996 & 1.000 & 0.983 & 0.976 & 0.970 \\
\hline & 1997 & 0.995 & 1.000 & 0.992 & 0.986 \\
\hline & 1998 & 0.993 & 0.998 & 1.000 & 0.994 \\
\hline & 1999 & 0.992 & 0.997 & 0.999 & 1.000 \\
\hline \multirow[t]{4}{*}{$\mathrm{PTA}_{1,2}$} & 1996 & 1.000 & 0.984 & 0.977 & 0.972 \\
\hline & 1997 & 0.995 & 1.000 & 0.993 & 0.987 \\
\hline & 1998 & 0.994 & 0.998 & 1.000 & 0.994 \\
\hline & 1999 & 0.994 & 0.998 & 0.999 & 1.000 \\
\hline \multirow{4}{*}{ PTA $_{1,2,3}$} & 1996 & 1.000 & 0.985 & 0.978 & 0.973 \\
\hline & 1997 & 0.995 & 1.000 & 0.993 & 0.988 \\
\hline & 1998 & 0.994 & 0.999 & 1.000 & 0.995 \\
\hline & 1999 & 0.994 & 0.998 & 0.999 & 1.000 \\
\hline \multirow{4}{*}{$\mathrm{PTA}_{2}$} & 1996 & 1.000 & 0.978 & 0.969 & 0.962 \\
\hline & 1997 & 0.989 & 1.000 & 0.989 & 0.983 \\
\hline & 1998 & 0.989 & 0.997 & 1.000 & 0.992 \\
\hline & 1999 & 0.989 & 0.997 & 0.999 & 1.000 \\
\hline \multirow{4}{*}{$\mathrm{PTA}_{3}$} & 1996 & 1.000 & 0.964 & 0.952 & 0.943 \\
\hline & 1997 & 0.987 & 1.000 & 0.984 & 0.974 \\
\hline & 1998 & 0.984 & 0.996 & 1.000 & 0.988 \\
\hline & 1999 & 0.982 & 0.995 & 0.998 & 1.000 \\
\hline \multirow{4}{*}{ PTA $_{\text {official }}$} & 1996 & 1.000 & 0.965 & 0.951 & 0.947 \\
\hline & 1997 & 0.978 & 1.000 & 0.986 & 0.977 \\
\hline & 1998 & 0.967 & 0.995 & 1.000 & 0.990 \\
\hline & 1999 & 0.958 & 0.990 & 0.998 & 1.000 \\
\hline
\end{tabular}

${ }^{1} \mathrm{PTA}_{1}=$ PTA based on first-parity records, $\mathrm{PTA}_{1,2}=$ PTA based on first- and second-parity records, PTA $_{1,2,3}=$ PTA based on first-, second-, and third-parity records, PTA $_{2}=$ PTA for second-parity lactation, $\mathrm{PTA}_{3}=$ PTA for third-parity lactation, and PTA official = official USDA-DHIA PTA.

tween the same year pairs, correlations generally were lower for official PTA (0.947 to 0.998) than for tailored PTA (0.970 to 0.999) regardless of the number of bull daughters; i.e., the tailored evaluations were more stable across time. However, for $\mathrm{PTA}_{3}$, correlations between the same year pairs were higher for official PTA of bulls with $\geq 10$ daughters. That result suggests that differences in maturity rates of daughters may have been estimated well for bulls with many daughters, but apparent differences in maturity rate for bulls with few daughters may be attributable to residual environmental effects or random error. Correlations between PTA were lower between 1996 and 1997 than between 1997 and 1998 or between 1998 and 1999, most likely because reliabilities for the same bulls were higher in later years. Higher initial reliability was associated with smaller increases in reliability in subsequent years. When information from more than a single parity was included in the tailored PTA, correlations were higher across time.

Mean number of parities per daughter across time for each bull was more uniform for tailored evaluations than for official evaluations. For bulls born after 1984 and with $\geq 10$ daughters, mean number of records per daughter in the PTA was 1.69 with an SD of 0.08 for $\mathrm{PTA}_{1,2}$ and 2.13 with an SD of 0.15 for $\mathrm{PTA}_{1,2,3}$. In contrast, official USDA evaluations had 2.04 records per daughter with an SD of 0.58. Similarly, for bulls with $\geq 500$ daughters, mean number of records per daughter were 1.69 with an SD of 0.04 for $\mathrm{PTA}_{1,2}, 2.12$ with an SD of 0.08 for $\mathrm{PTA}_{1,2,3}$, and 1.78 with an SD of 0.45 for official USDA evaluations. Increased uniformity should help to produce more consistency in the proportion of information from various parities and thus more stability if genetic differences exist for maturity rate of daughters.

Official PTA included information from up to 5 parities per daughter, whereas the tailored PTA included information from only 1,2 , or 3 parities. The confounding between number of parities with information included in the evaluation did not allow differentiation of contributions from fourth and fifth parities. Thus, the question of how many parities are needed to optimize genetic merit could not be resolved. Some of the greater variation in official PTA also could have resulted from differences in persistency, which would not have affected tailored PTA as those were based on complete lactations.

Cumulative-parity evaluations ( $\mathrm{PTA}_{1,2}$ and $\left.\mathrm{PTA}_{1,2,3}\right)$ had higher correlations between the same year pairs than did evaluations that represented individual-parity contributions $\left(\mathrm{PTA}_{2}\right.$ and $\left.\mathrm{PTA}_{3}\right)$. Not surprisingly, when 
Table 8. Standard deviations of differences between PTA milk (kg) for evaluations tailored to different parities and official evaluations for bulls born after 1984 with $\geq 10$ (above diagonal; $\mathrm{n}=8072$ ) or $\geq 500$ daughters (below diagonal; $\mathrm{n}=211$ ) that first calved before 1996, 1997, 1998, or $1999 .^{1}$

\begin{tabular}{|c|c|c|c|c|c|}
\hline & \multirow[b]{2}{*}{ Year } & \multicolumn{4}{|c|}{ Year } \\
\hline & & 1996 & 1997 & 1998 & 1999 \\
\hline \multirow[t]{4}{*}{$\mathrm{PTA}_{1}$} & 1996 & - & 52 & 62 & 69 \\
\hline & 1997 & 28 & - & 35 & 47 \\
\hline & 1998 & 34 & 17 & - & 31 \\
\hline & 1999 & 36 & 22 & 10 & - \\
\hline \multirow[t]{4}{*}{$\mathrm{PTA}_{1,2}$} & 1996 & - & 50 & 59 & 66 \\
\hline & 1997 & 27 & - & 33 & 44 \\
\hline & 1998 & 30 & 15 & - & 29 \\
\hline & 1999 & 32 & 19 & 9 & - \\
\hline \multirow{4}{*}{$\mathrm{PTA}_{1,2,3}$} & 1996 & - & 49 & 59 & 66 \\
\hline & 1997 & 27 & - & 33 & 43 \\
\hline & 1998 & 31 & 15 & - & 29 \\
\hline & 1999 & 32 & 18 & 9 & - \\
\hline \multirow{4}{*}{$\mathrm{PTA}_{2}$} & 1996 & - & 67 & 79 & 87 \\
\hline & 1997 & 44 & - & 45 & 58 \\
\hline & 1998 & 44 & 21 & - & 40 \\
\hline & 1999 & 45 & 22 & 12 & - \\
\hline \multirow[t]{4}{*}{$\mathrm{PTA}_{3}$} & 1996 & - & 96 & 111 & 120 \\
\hline & 1997 & 53 & - & 63 & 81 \\
\hline & 1998 & 59 & 28 & - & 55 \\
\hline & 1999 & 63 & 36 & 19 & - \\
\hline \multirow{4}{*}{$\mathrm{PTA}_{\text {official }}$} & 1996 & - & 74 & 90 & 91 \\
\hline & 1997 & 63 & - & 48 & 61 \\
\hline & 1998 & 74 & 29 & - & 41 \\
\hline & 1999 & 80 & 42 & 19 & - \\
\hline
\end{tabular}

${ }^{1} \mathrm{PTA}_{1}=$ PTA based on first-parity records, $\mathrm{PTA}_{1,2}=$ PTA based on first- and second-parity records, $\mathrm{PTA}_{1,2,3}=$ PTA based on first-, second-, and third-parity records, $\mathrm{PTA}_{2}=$ PTA for second-parity lactation, $\mathrm{PTA}_{3}=$ PTA for third-parity lactation, and $\mathrm{PTA}_{\text {official }}=$ official USDA-DHIA PTA.

more records were included, the results were more stable. Some additional variation in $\mathrm{PTA}_{2}$ and $\mathrm{PTA}_{3}$ may have developed because they were derived from cumulative-parity estimates and no effort was made to consider differences in numbers of contemporaries, DIM, or accuracy of herd testing information for all animals.

Table 8 gives another representation of the stability of relationships across time expressed as SD of differences in PTA. The outcome was much the same as shown in Table 7: as the correlations increased, SD of PTA differences decreased. The more time between evaluations, the greater the increase in SD of PTA differences. As more parities were included in PTA, SD of differences declined slightly. For the same year pairs, official PTA had larger SD than did tailored evaluations. For example, for bulls with $\geq 10$ daughters, SD of differences in $\mathrm{PTA}_{1}, \mathrm{PTA}_{1,2}$, or $\mathrm{PTA}_{1,2,3}$ between 1996 and 1999 were 69,66 , and $66 \mathrm{~kg}$, respectively, whereas SD of official PTA was $91 \mathrm{~kg}$. Even more strikingly, for bulls with $\geq 500$ daughters, the corresponding SD of PTA differences were $36,32,32$, and $80 \mathrm{~kg}$; SD of official PTA differences were 2.2 to 2.5 times greater than for the 3 tailored PTA (i.e., variance was 5 to 6 times greater). Accounting for differences in maturity rate might eliminate most of the remaining changes in PTA for bulls with high reliability, but the same should not be expected for bulls with 10 to 50 daughters.

\section{CONCLUSIONS}

Differences in maturity rate of bull daughters were examined to determine how they influence change in bull evaluations across time. Bull evaluations tailored to include only specific parities were found to be more uniform across years for records per daughter than were official USDA-DHIA PTA and were more stable based on correlations or SD of PTA differences. Tailored evaluations for bulls with $\geq 500$ daughters were more stable across time; that is, they had $<20 \%$ of the variance of official PTA differences. Nevertheless, any number of environmental effects could be associated with daughters of an individual bull so that bulls might appear to transmit differently for maturity rate than they actually do. Further research is needed to confirm that apparent differences among bulls in the maturity rate of daughters are genetic. A study is currently underway to determine how the same bulls with daughters in multiple countries compare based on progeny performance from various parities. If daughter maturity rate is confirmed to be genetic, modification of the evaluation 
model to account for that trait should improve stability and accuracy of evaluations. However, differences among results from preliminary studies at the Animal Improvement Programs Laboratory must be resolved before a modification to deal with maturity rate can be implemented in the USDA-DHIA evaluation model.

\section{ACKNOWLEDGMENTS}

The cooperation of the US dairy industry in supplying yield and pedigree data through the National Genetic Improvement Program for use in calculation of genetic evaluations is acknowledged. The assistance of J. H. Megonigal, Jr., and L. M. Walton in calculating parity evaluations and of S. M. Hubbard and others in manuscript review is appreciated.

\section{REFERENCES}

Abdallah, J. M., and B. T. McDaniel. 2002. Heritability of changes in genetic evaluations of dairy bulls from first to later records of daughters. J. Dairy Sci. 85:951-957.

Animal Improvement Programs Laboratory. 2005. USDA yield evaluation description (Feb 2005). Online. Available http://aipl. arsusda.gov/reference/yield.htm. Accessed March 31, 2005.

Auvray, B., and N. Gengler. 2002. Feasibility of a Walloon test-day model and study of its potential as tool for selection and management. Interbull Bull. 29:123-127.

Carlen, E., E. Strandberg, and A. Roth. 2004. Genetic parameters for clinical mastitis, somatic cell score, and production in the first three lactations of Swedish Holstein cows. J. Dairy Sci. 87:3062-3070.

Cassell, B. G., J. S. Clay, and H. D. Norman. 1985. Differences in Modified Contemporary Comparison sire evaluations from first and later lactations by breed. J. Dairy Sci. 68:1778-1784.

Cassell, B. G., and B. T. McDaniel. 1983. Use of later records in dairy sire evaluation: A review. J. Dairy Sci. 66:1-10.

Cassell, B. G., B. T. McDaniel, and H. D. Norman. 1983. Modified contemporary comparison sire evaluations from first, all, and later lactations. J. Dairy Sci. 66:140-147.

de Roos, A. P. W., A. G. F. Harbers, and G. de Jong. 2001. Random regression test-day model in The Netherlands. Interbull Bull. 27:155-159.

Division of DHI Investigations. 1937. List of sires proved in Dairy Herd Improvement Associations, 1935-37. USDA Misc. Publ. No. 277. USDA, Washington, DC.

Druet, T., F. Jaffrezic, and V. Ducrocq. 2005. Estimation of genetic parameters for test day records of dairy traits in the first three lactations. Genet. Sel. Evol. 37:257-271.
Guo, Z., M. S. Lund, P. Madsen, I. Korsqaard, and J. Jensen. 2002. Genetic parameter estimation for milk yield over multiple parities and various lengths of lactation in Danish Jerseys by random regression models. J. Dairy Sci. 85:1596-1606.

Henderson, C. R., O. Kempthorne, S. R. Searle, and C. M. von Krosigk. 1959. The estimation of environmental and genetic trends from records subject to culling. Biometrics 15:192-218.

International Bull Evaluation Service. 2005. Description of National Genetic Evaluation Systems for dairy cattle traits as applied in different Interbull member countries. Online. Available http:// www-interbull.slu.se/national_ges_info2/begin-ges.html. Accessed March 28, 2005.

Jamrozik, J., L. R. Schaeffer, and F. Grignola. 1998. Genetic parameters for production traits and somatic cell score of Canadian Holsteins with multiple trait random regression model. Proc. 6th World Congr. Genet. Appl. Livest. Prod. 23:303-306.

Keown, J. F., H. D. Norman, and R. L. Powell. 1976. Effects of selection bias on sire evaluation procedures. J. Dairy Sci. 59:1808-1816.

Liu, Z., F. Reinhardt, and R. Reents. 2000. Estimating parameters of a random regression test day model for the first three lactation milk production traits using the covariance function approach. Interbull Bull. 25:74-80.

Powell, R. L., and H. D. Norman. 2001. Stability and bias of yield evaluations for Holstein bulls in artificial insemination service. J. Dairy Sci. 84 (Aug.). Online.

Powell, R. L., A. H. Sanders, and H. D. Norman. 2004. Stability of genetic evaluations for active artificial insemination bulls. J. Dairy Sci. 87:2614-2620.

Schaeffer, L. R., J. Jamrozik, G. J. Kistemaker, and B. J. Van Doormaal. 2000. Experience with a test-day model. J. Dairy Sci. 83:1135-1144.

Strabel, T., E. Ptak, J. Szyda, and J. Jamrozik. 2004. Multiple-lactation random regression test-day model for Polish Black and White cattle. Interbull Bull. 32:133-137.

Strandberg, E. 1991. Breeding for lifetime performance in dairy cattle. Ph.D. Thesis. Swedish University of Agricultural Sciences, Uppsala, Sweden.

VanRaden, P. M. 1997. Lactation yields and accuracies computed from test day yields and (co)variances by best prediction. J. Dairy Sci. 80:3015-3022.

Weller, J. I., and E. Ezra. 2004. Genetic analysis of the Israeli Holstein dairy cattle population for production and nonproduction traits with a multitrait animal model. J. Dairy Sci. 87:1519-1527.

Wiggans, G. R., and P. M. VanRaden. 1989. USDA-DHIA animal model genetic evaluations. Natl. Coop. DHI Progr. Handbook, Fact Sheet H-2. Ext. Serv., USDA, Washington, DC.

Wiggans, G. R., and P. M. VanRaden. 2004a. Accounting for differences in rate of maturity in yield evaluations. Online. Available http://aipl.arsusda.gov/publish/presentations/ADSA04/ ADSA04_grw.htm. Accessed March 31, 2005.

Wiggans, G. R., and P. M. VanRaden. 2004b. Accounting for differences in rate of maturity in yield evaluations. J. Dairy Sci. 87(Suppl. 1):412. (Abstr.) 